\title{
Effects of Intellectual Capital and University Knowledge on Indigenous Innovation: Evidence from Indian SMEs
}

\begin{abstract}
Intellectual capital and collaboration with universities are vital knowledge management practices for small and medium-sized enterprises (SMEs) to innovate and improve the effectiveness of their operations. This study investigates empirically the impacts of intellectual capital and university knowledge on indigenous innovation and how business and institutional environments affect the relationships. The research model is tested using moderated regression analysis and data collected from 150 SMEs in India. The results show that intellectual capital and university knowledge improve indigenous innovation both individually and interactively. The effect of intellectual capital on indigenous innovation is amplified by dysfunctional competition whereas the effect of university knowledge on indigenous innovation is attenuated by environmental uncertainty. In addition, we find that indigenous innovation is positively associated with business performance. The impact of indigenous innovation on business performance is enhanced by dysfunctional competition but reduced by environmental uncertainty.
\end{abstract}

Keywords: intellectual capital, university knowledge, indigenous innovation, dysfunctional competition, environmental uncertainty

\section{Introduction}

Small and medium-sized enterprises (SMEs) play significant roles in Indian economic development (Mathur, Mittal, and Dangayach 2012; Ministry of Micro Small and Medium Enterprises 2016). Indian SMEs contribute about $8 \%$ to GDP and $40 \%$ to the exports from the country (Small and Medium Business Development Chamber of India 2016). The government of India has introduced policies to transform India into a knowledge-based economy and Indian firms have demonstrated rising levels of indigenous innovation performance and been experiencing a significant increase in the use of intellectual property (IP) (Dutta, Lanvin, and Wunsch-Vincent 2015). Indigenous innovation is generated using firms' internal resources and 
capabilities ( $\mathrm{Li}$ et al. 2010; Li et al. 2011). It is viewed as an important way for developing and sustaining competitive advantages in emerging markets such as India and requires specialised knowledge inputs from both internal and external sources (Li et al. 2010; McMahon and Thorsteinsdóttir 2013). Intellectual capital, which reflects a firm's internal knowledge stock (Youndt, Subramaniam, and Snell 2004), and collaboration with universities are important knowledge management practices that enable Indian SMEs to develop indigenous innovations, improve the effectiveness of their operations, and gain competitive advantages (Liu et al. 2014; Aboelmaged 2014; Subramaniam and Youndt 2005).

Universities have been recognised as important knowledge sources for SMEs (Parayil and D'Costa 2009; Alexander and Childe 2013; Ahrweiler, Pyka, and Gilbert 2011; Un, CuervoCazurra, and Asakawa 2010). India has the third largest higher education system in the world and the Indian government has invested heavily in universities (World Bank 2015). Universities can act as essential components of Indian SMEs' knowledge chains to help them to develop new products and processes (Un and Asakawa 2015; Maietta 2015; Liu et al. 2014). Although empirical evidence exists that knowledge transfer between universities and firms is affected by the firms' existing knowledge (Ahrweiler, Pyka, and Gilbert 2011; Sherwood and Covin 2008; Bruneel, D'Este, and Salter 2010; McMahon and Thorsteinsdóttir 2013), few studies have investigated how intellectual capital and university knowledge jointly influence indigenous innovation.

The judicial procedures in India tend to be protracted, costly, and highly vulnerable to political influences and pressures (Kozhikode and Li 2012), with corruption severely affecting law enforcement in some areas (Miller and Kim 2016). India therefore lacks market-supporting institutions to protect IP and other business interests (Dutta, Lanvin, and Wunsch-Vincent 2015). Indian SMEs may face opportunistic, unethical, or even unlawful competitive behaviour in markets (Miller and Kim 2016; World Bank 2014). As India has experienced high speed economic growth recently (World Bank 2015), market and technological environments are changing rapidly and are more uncertain (Chen and Paulraj 2004). Researchers argue that the effectiveness of university-industry collaboration (Maietta 2015; Alexander and Childe 2013) and the profitability of innovation (Teece 1986) are influenced by institutional and business environments. However, much less research has focused on how dysfunctional competition and environmental uncertainty influence the relationships among intellectual capital, university knowledge, indigenous innovation, and business performance.

Indian SMEs are forced to enhance their performance and competitiveness through innovation because of increasing domestic and global competition (Kumar et al. 2006; Desai 
2008; Mathur, Mittal, and Dangayach 2012). Innovation is a challenge for Indian SMEs because they typically lack capabilities, resources, knowledge, and expertise (Thakkar, Kanda, and Deshmukh 2013; Garengo and Sharma 2014). Therefore, how to manage and leverage internal and external knowledge to innovate becomes a critical challenge faced by Indian SEMs (Alexander and Childe 2013; Thakkar, Kanda, and Deshmukh 2013; Liu et al. 2014). In addition, Indian SMEs have to manage knowledge and innovate in fast changing market and technological environments and underdeveloped institutional contexts, which is another challenge for them to tackle (Kozhikode and Li 2012; World Bank 2015). The objective of this study is to explore empirically the impacts of intellectual capital and university knowledge on indigenous innovation and how environmental conditions affect these relationships. This study addresses three research questions. First, how do intellectual capital and university knowledge jointly affect indigenous innovation? Second, what is the effect of indigenous innovation on business performance? Third, how do dysfunctional competition and environmental uncertainty influence such effects? The findings provide empirical evidence that Indian SMEs can gain competitive advantages through indigenous innovation. We also find that intellectual capital and university knowledge increase indigenous innovation both individually and interactively, which can help Indian SMEs to improve the effectiveness of knowledge management. The results of the moderating effects of dysfunctional competition and environmental uncertainty can provide guidelines for Indian SMEs to optimise knowledge management and innovation decisions according to business and institutional environments.

\section{Theoretical background and research hypotheses}

\subsection{Literature review}

Intellectual capital refers to the sum of knowledge a firm is able to leverage, including the knowledge held by individuals (i.e. human capital), storing within organisational processes and structures (i.e. structural capital), and residing in social relationships (i.e. social capital) (Hsu and Sabherwal 2012; Subramaniam and Youndt 2005). Researchers find that intellectual capital is positively associated with innovation and business performance. For example, Subramaniam and Youndt (2005) report that the components of intellectual capital and their interrelationships selectively influence incremental and radical innovative capabilities. Lee, Swink, and Pandejpong (2011) find that the components of intellectual capital jointly affect the technical success of manufacturing process innovation projects. Hsu and Sabherwal (2012) reveal that intellectual capital positively affects knowledge management and dynamic 
capabilities which improve innovation. Hsu and Wang (2012) discover that dynamic capability mediates the impact of intellectual capital on performance.

Empirical evidence exists that research and development (R\&D) collaboration with universities can help a firm to develop new knowledge and innovate. For example, Un, CuervoCazurra, and Asakawa (2010) and Un and Asakawa (2015) find that R\&D collaboration with universities has positive impacts on product and process innovation. Al-Ashaab et al. (2011) propose a balanced scorecard method to measure the outcomes of university-industry collaboration and show that firms would like to enhance the degree of collaboration with universities. Ahrweiler, Pyka, and Gilbert (2011) discover that linkages with universities increase the variety of knowledge among firms and innovation diffusion in terms of quantity and speed. Alexander and Childe (2013) argue that selecting the appropriate channels for acquiring knowledge from universities can improve innovation. Maietta (2015) examines how local university activities affect firm innovation inputs and outputs and finds that geographical proximity from a firm to a local university positively affects product innovation.

Dysfunctional competition refers to the unfair or illegal competitive practices, such as patent and copyright violation, widespread copy of original innovations, and breach of contracts or agreements, in markets (Li and Atuahene-Gima 2001). Researchers argue that it is a critical contextual factor that influences firms' innovation behaviour in emerging markets. For example, Li and Atuahene-Gima (2001) propose that the relationship between product innovation strategy and the performance of new technology ventures is moderated by dysfunctional competition. Sheng, Zhou, and Lessassy (2013) find that dysfunctional competition enhances the impact of new product development (NPD) speed on firm performance. Zhang et al. (2017) report that dysfunctional competition reduces the positive impacts of institutional support on product and process innovation.

Environmental uncertainty refers to the rate of change and the degree of instability in the business environment (Chen and Paulraj 2004). Researchers argue that uncertainty is an important environmental contingency that has significant impacts on innovation. For example, $\mathrm{Li}$ and Atuahene-Gima (2001) find that uncertainty positively moderates the relationship between product innovation strategy and the performance of new technology ventures. Wang, Yeung, and Zhang (2011) report that environmental uncertainty enhances the impacts of trust on a firm's innovation performance. Sheng, Zhou, and Lessassy (2013) find that uncertainty attenuates the impact of NPD speed on firm performance.

Researchers have developed different methods, techniques, systems, and practices to improve the efficiency and effectiveness of Indian SMEs' operations. For example, Kumar et 
al. (2006) propose a Lean Sigma method to reduce the defect occurring in the final product. Desai (2008) develops a cost of quality system to measure the performance of SMEs. Mathur, Mittal, and Dangayach (2012) propose a simple scheduling heuristic to improve SMEs' productivity. Thakkar, Kanda, and Deshmukh (2013) investigate how supply chain management has been perceived within Indian SMEs and identify a set of critical success factors. Garengo and Sharma (2014) find that environmental changes push Indian SMEs to develop performance measurement systems without affecting the corporate governance structure.

\subsection{Knowledge-based view and contingency theory}

The hypotheses regarding the relationships among university knowledge, intellectual capital, indigenous innovation, and business performance, and the moderating effects of dysfunctional competition and environmental uncertainty are developed using a knowledgebased view (KBV) of the firm and contingency theory. The KBV argues that knowledge is a strategic resource and a primary source of innovation (Grant 1996; Zahra and George 2002). It considers firms as the mechanisms that facilitate the integration, transfer, and creation of knowledge (Nonaka 1994; Zahra and George 2002). Knowledge is heterogeneously distributed among firms and their knowledge chains, and the firms who have more knowledge depositories and higher capabilities in knowledge integration and creation will gain sustainable competitive advantages (Nonaka 1994; Nahapiet and Ghoshal 1998). Intellectual capital and university knowledge are critical internal and external knowledge that firms can leverage (Hsu and Sabherwal 2012; Un and Asakawa 2015). Hence, we argue that both intellectual capital and university knowledge directly improve indigenous innovation. In addition, the KBV indicates that a firm's capability to integrate and utilise external knowledge is influenced by its prior knowledge base (Zahra and George 2002; Zhang et al. 2015). Intellectual capital represents the knowledge accumulated in a firm and hence it facilitates a firm to absorb university knowledge and to fully reap its value on innovation (Hsu and Sabherwal 2012; Subramaniam and Youndt 2005). Universities can also provide complementary knowledge and skills which enable a firm to implement existing knowledge creatively, enhancing the value of intellectual capital (Sherwood and Covin 2008). Hence, we argue that intellectual capital and university knowledge are complementary in enhancing indigenous innovation.

Contingency theory explains variations in business performance from the perspective of the interactions between firms and environments (Kaste and Rosenzweig 1985; Lawrence and Lorsch 1986). This theory argues that firms are open systems that are in interaction with task environments and that the processes and decisions of firms must fit with environmental 
contexts (Kaste and Rosenzweig 1985). It indicates that firms are subjected to a variety of environmental influences which affect the effectiveness of their knowledge management practices and the profitability of innovations (Teece 1986). The appropriate fit between firms' practices and external environments helps the firms to achieve sustainable competitive advantages (Lawrence and Lorsch 1986). The perceived uncertainty and dysfunctional competition have been recognised as important environmental factors that influence the effects of knowledge management practices and innovation (Wang, Yeung, and Zhang 2011; Sheng, Zhou, and Lessassy 2013; Nahapiet and Ghoshal 1998; Lawrence and Lorsch 1986). Therefore, we argue that environmental uncertainty and dysfunctional competition moderate the impacts of intellectual capital and university knowledge on indigenous innovation and the impact of indigenous innovation on business performance.

\subsection{The impacts of intellectual capital and university knowledge on indigenous innovation}

Intellectual capital can provide the knowledge that is critical for indigenous innovation. Highly skilled employees possess special knowledge and capabilities and hence can identify and capture new market and technological opportunities and transform them into innovative products and processes (Lee, Swink, and Pandejpong 2011). India has around 3,500 engineering colleges and 2,500 management institutes and can produce millions of engineers and MBA graduates every year (Forbes 2014). Indian SMEs can innovate by relying on massive amounts of low-cost but talented employees. The manufacturing sectors have been growing rapidly in India in recent decades (World Bank 2015). This enables SMEs to accumulate knowledge in organisational processes and databases. They can not only guide the implementation of cross-functional teams on product and process innovation but also help employees to reuse existing knowledge creatively (Youndt, Subramaniam, and Snell 2004). Indian culture is characterized by collectivism and thus the social relations among employees enable them to access each other's private and personal knowledge and provide opportunities for knowledge exchange and combination within firms (Nahapiet and Ghoshal 1998; Parayil and D'Costa 2009). SMEs with higher levels of intellectual capital have higher internal capabilities to introduce new products in intra-organisational settings (Aboelmaged 2014; Li et al. 2010). Intellectual capital thus can be explored and exploited for indigenous innovation (Youndt, Subramaniam, and Snell 2004). Therefore, we propose the following hypothesis.

\section{H1: Intellectual capital improves indigenous innovation.}

Higher education has grown rapidly in India over the last 30 years and universities provide Indian SMEs with a stable scientific and technological foundation for innovation (Forbes 2014; Dutta, Lanvin, and Wunsch-Vincent 2015). Academic researchers specialise in generating deep 
and complex knowledge to be shared through presentations and publications (Ahrweiler, Pyka, and Gilbert 2011). Universities thus possess a broad knowledge base (Kotha, George, and Srikanth 2013) and can provide SMEs with a wide array of technological knowledge (Ahrweiler, Pyka, and Gilbert 2011; Un and Asakawa 2015). In this way, university knowledge can help Indian SMEs to develop internal capabilities by recombining different disciplines (Alexander and Childe 2013; Maietta 2015; Forbes 2014). This can introduce pluralism in mental models and promote creativity, enhancing indigenous innovation (Bruneel, D'Este, and Salter 2010; Liu et al. 2014). Therefore, we propose the following hypothesis.

\section{H2: University knowledge improves indigenous innovation.}

Universities can provide SMEs the knowledge they lack, such as methods for implementing new technologies and procedures for troubleshooting (Kotha, George, and Srikanth 2013; Sherwood and Covin 2008). University knowledge thus allows SMEs to view existing knowledge from fresh perspectives (Ahrweiler, Pyka, and Gilbert 2011). University knowledge can bring employees new technological skills that allow them to use current knowledge innovatively. The technology specifications and step-by-step troubleshooting procedures acquired from universities enable SMEs to optimise existing organisational processes and structures for innovation (Subramaniam and Youndt 2005). Social relations facilitate employees to integrate and internalise knowledge (Nonaka 1994; Nahapiet and Ghoshal 1998). Universities can provide valuable knowledge in distant knowledge domains which requires assimilation and transformation through social interactions among employees (Zahra and George 2002; Kotha, George, and Srikanth 2013). Hence the value of social capital is enhanced by university knowledge (Nahapiet and Ghoshal 1998). Therefore, university knowledge allows a SME to exploit intellectual capital creatively and amplifies its value on indigenous innovation. In addition, researchers argue that a firm's knowledge base facilitates the firm to absorb external knowledge (Zahra and George 2002). Universities can provide both tacit and explicit knowledge (Sherwood and Covin 2008). Employees with high competence and skills can recognise and identify valuable university knowledge and assimilate and apply the knowledge, enhancing the impact of university knowledge on innovation (Maietta 2015; Aboelmaged 2014). Existing technical manuals, archives, and databases help a SME to combine and implement the explicit knowledge obtained from universities, such as specifications and documentation of technologies and step-by-step procedures for troubleshooting (Hsu and Wang 2012). Social relations among employees facilitate them to internalise and assimilate tacit university knowledge, such as unstated or unwritten methods for technology implementation (Zhang et al. 2015). Hence the components of intellectual 
capital jointly help a SME to absorb university knowledge, enhancing its effects on indigenous innovation (Youndt, Subramaniam, and Snell 2004). Therefore, we propose the following hypothesis.

H3: Intellectual capital and university knowledge are complementary in improving indigenous innovation.

\subsection{The impact of indigenous innovation on business performance}

With the rise of the Indian economy, Indian SMEs have shifted to innovation to gain competitive advantages (Prahalad and Mashelkar 2010; Mathur, Mittal, and Dangayach 2012). Because India has a large low income population, highly diversified local markets, and a tradition of jugaad (i.e. developing alternatives, improvisations, and make-dos to overcome a lack of resources), Indian SMEs tend to develop affordable and sustainable products that are accessible to a greater number of people with fewer resources (Prahalad and Mashelkar 2010). Indian SMEs are more likely to develop simple, cheap, and convenient products indigenously because copying existing product designs cannot fulfil the unique requirements of local customers (Parayil and D'Costa 2009). In this way, indigenous innovations enable Indian SMEs to penetrate mass markets, increasing sales and market share. Indigenous innovations are based on a firm's own patents and hence can bring the firm first-mover advantages and exclusive rights that can increase profit and return on investment ( $\mathrm{Li}$ et al. 2011; Li et al. 2010). In addition, the Indian policy makers have targeted economic growth through indigenous innovation and programs have been introduced to support the commercialisation of innovations (Dutta, Lanvin, and Wunsch-Vincent 2015; Parayil and D'Costa 2009). Indigenous innovations thus can help Indian SMEs to acquire resources and support from government, which can be used to improve their operations. Therefore, we propose the following hypothesis.

H4: Indigenous innovation improves business performance.

\subsection{The moderating effects of dysfunctional competition}

This study conceptualises dysfunctional competition as managers' perception about the overall opportunistic and unlawful competitive practices in markets. Formal market-supporting institutions have not been established in India and local authorities and firms may constitute a loosely coupled coalition of interest groups (Kozhikode and Li 2012). The interpretation and execution of rules and regulations are largely subject to local authorities' discretion (Miller and Kim 2016). Hence illegal practices may not be severely punished or even be protected in India due to a lack of rule of law and corrupt officials (Dutta, Lanvin, and Wunsch-Vincent 2015; Parayil and D'Costa 2009). Indian SMEs face high risks of knowledge spill-over or leakage because it is difficult to manage $R \& D$ collaboration using formal control mechanisms when 
dysfunctional competition is intense ( $\mathrm{Li}$ and Atuahene-Gima 2001; Li et al. 2011) and they lack market power and resources to protect themselves (Thakkar, Kanda, and Deshmukh 2013; Mathur, Mittal, and Dangayach 2012). Academic researchers have a tradition of knowledge sharing (Ahrweiler, Pyka, and Gilbert 2011). They may leak a SME's knowhow to outsiders unintentionally who may copy the SME's new product ideas (Li and Atuahene-Gima 2001). Hence SMEs have less motivation to use university knowledge and may rely more on intellectual capital for indigenous innovation when dysfunctional competition is intense. Therefore, we propose the following hypotheses.

H5a: Dysfunctional competition enhances the impact of intellectual capital on indigenous innovation.

H5b: Dysfunctional competition reduces the impact of university knowledge on indigenous innovation.

The efficacy of legal mechanisms for IP protection and contract enforcement is low in India (Kozhikode and Li 2012). For example, on average it takes 46 procedures and 1,420 days and costs $36.9 \%$ of the total claims to enforce a contract in India (World Bank 2014). Because of unfair competitive behaviour, such as copycat and counterfeit, collaborative innovation can be risky as partners may behave opportunistically and leak a SME's new product designs to its competitors (Li and Atuahene-Gima 2001). A SME cannot enjoy exclusive rights and improve profit and market share for a long time if its new products are illegally copied by competitors (Li and Atuahene-Gima 2001). Ineffective market competition laws also make it difficult for the SME to punish illegal imitators and gain compensation through legal means (Sheng, Zhou, and Lessassy 2013). Indigenous innovation enables a SME to better protect its IP because it is developed in intra-organisational settings ( $\mathrm{Li}$ et al. 2010) and hence plays a more important role in improving business performance when dysfunctional competition is intense. Therefore, we propose the following hypothesis.

H5c: Dysfunctional competition enhances the impact of indigenous innovation on business performance.

\subsection{The moderating effects of environmental uncertainty}

This study conceptualises environmental uncertainty as managers' perception about the overall unpredictability and rate of change of markets and technologies. It is difficult for a SME to rely on intellectual capital to develop new products in a volatile environment because fulfilling new customer needs often requires skills and expertise that are beyond the SME's current knowledge domain (Teece 1986; Wang, Yeung, and Zhang 2011). In an uncertain environment, intellectual capital may become obsolete quickly and thus is unable to produce 
innovations that enable a SME to keep up with the changing market environments and new trends in technology development (Lee, Swink, and Pandejpong 2011; Hsu and Sabherwal 2012). A SME thus tends to rely on new knowledge and resources acquired through collaboration with universities (Bruneel, D'Este, and Salter 2010; Alexander and Childe 2013). University knowledge allows a SME to obtain advanced technologies and grasp the technology development direction in its industry (Maietta 2015). For example, methods and procedures for technology implementation allow SMEs to apply advanced technologies to develop new products and patents to meet new customer requirements (Sherwood and Covin 2008; Un and Asakawa 2015). Hence, when environmental uncertainty is high, the value of university knowledge becomes greater because it allows a SME to improve internal capabilities and knowledge to match with new environments and to develop innovations to profit from market dynamics (Wang, Yeung, and Zhang 2011; Un, Cuervo-Cazurra, and Asakawa 2010). Therefore, we propose the following hypotheses.

H6a: Environmental uncertainty reduces the impact of intellectual capital on indigenous innovation.

H6b: Environmental uncertainty enhances the impact of university knowledge on indigenous innovation.

The high speed economic development, growing urban population, and the large and diversified local markets indicate that Indian customers' requirements are very difficult to predict (Prahalad and Mashelkar 2010; Parayil and D'Costa 2009). Indigenous innovations are constrained by a firm's existing competence and experiences and hence may not be able to fulfil customers' changing requirements when environmental uncertainty is high (Li et al. 2011; Wang, Yeung, and Zhang 2011). When customer preferences and technologies change quickly, it is difficult for a SME to predict the evolution of markets and adjust investments in internal capabilities accordingly (Chen and Paulraj 2004). Product life cycles are shortened and the value of a SME's own patents decreases quickly in a volatile environment (Teece 1986). Hence indigenous innovations cannot significantly increase sales and market share and bring competitive advantages for a long time. Therefore, we propose the following hypothesis.

H6c: Environmental uncertainty reduces the impact of indigenous innovation on business performance.

The conceptual framework and all proposed hypotheses are provided in Figure 1.

Insert Figure 1 here 


\section{Research method}

\subsection{Questionnaire design}

Based on the relevant literature, a survey instrument was designed to measure intellectual capital, university knowledge, indigenous innovation, business performance, environmental uncertainty, and dysfunctional competition. A multiple-item, 7-point Likert-type scale was employed to measure the constructs. The questionnaire included the demographic profile of the firm (i.e. industry, R\&D investment, training budget, and annual sales). The scales, which consist of 35 measurement items, are listed in the appendix.

Intellectual capital was operationalised as the knowledge residing in individuals, residing within organisational processes, and embedded within and available through employees' networks of relationships. Ten items indicating employees' skills and expertise, a firm's manuals, procedures, rules, databases, and systems, and the interactions and relationships among employees were used to measure intellectual capital. These items were adapted from Subramaniam and Youndt (2005). They capture the multidimensional nature of the concept and collectively reflect the knowledge stock and flows embedded in a firm (Hsu and Wang 2012; Lee, Swink, and Pandejpong 2011). The defining characteristic of indigenous innovation is that the source of innovation is a firm's own specific capabilities ( $\mathrm{Li}$ et al. 2010). Indigenous innovation was operationalised as the practice of indigenously developing new products using a firm's own resources and knowledge assets in intra-organisational settings ( $\mathrm{Li}$ et al. 2011). It was gauged by four items reflecting the extent to which a firm develops new products and patents using internal resources and capabilities ( $\mathrm{Li}$ et al. 2010; Li et al. 2011). Environmental uncertainty was operationalised as the fluctuations and variations in demand and the extent of technological changes (Chen and Paulraj 2004). It was measured with four items about the perceived unpredictability of market and demand and the speed of change of the technologies in the industry (Chen and Paulraj 2004). They capture the rate of change and the degree of instability in environments (Wang, Yeung, and Zhang 2011). The respondents were asked to indicate the degree of agreement with the statements describing intellectual capital, indigenous innovation, and environmental uncertainty ( $1=$ 'strongly disagree'; $7=$ 'strongly agree').

University knowledge was operationalised as the technological knowledge that a firm has successfully obtained through the university-industry links (Sherwood and Covin 2008). It was measured with eight items gauging the tacit and explicit knowledge related to technology implementation, troubleshooting, technology specifications, and documentation that a firm acquired from universities (Sherwood and Covin 2008). They capture the broad knowledge produced by universities that is important for a firm's innovation (Un, Cuervo-Cazurra, and 
Asakawa 2010). The respondents were asked to what extent their firms learned from universities ( $1=$ 'little'; $7=$ 'to a great extent'). Dysfunctional competition was operationalised as managers' perception of opportunistic or illegal activities in markets (Zhang et al. 2017). Four items about the extent to which firms experienced opportunistic, unfair, or unlawful activities in the last three years were used to measure dysfunctional competition ( $1=$ 'not at all'; $7=$ 'to a great extent') ( $\mathrm{Li}$ and Atuahene-Gima 2001). They evaluate the inadequacy of the legal framework and opportunism of the competitive behaviour of firms in a market. Business performance was operationalised as how well a firm achieves its market-oriented and financial goals. It was measured using profit, market share, return on investment, market share growth, and sales growth (Vickery et al. 2003). They evaluate a firm's profitability and market growth and are viewed as the final performance outcome. The respondents were asked to compare their firms' performance with major competitors over the past year ( $1=$ 'far worse'; $7=$ 'far better').

Firms who have invested more in $R \& D$ and training tend to have higher capabilities for indigenous innovation (Un and Asakawa 2015). We therefore included R\&D investment (i.e. percentage of annual sales invested in R\&D) and training budget (i.e. percentage of annual sales invested in training) as control variables in the analysis.

\subsection{Data collection}

We classified SMEs as manufacturing firms with 250 or less employees based on the definition in the Official Journal of the European Union (Thakkar, Kanda, and Deshmukh 2013; Wamba et al. 2016; Waehrens, Slepniov, and Johansen 2015). After pilot testing the questionnaire with 15 SMEs, it was decided to use one key informant per SME who was familiar with innovation and knowledge management practices and was knowledgeable about business and institutional environments. Such key informants could be general managers or directors, senior R\&D managers, operations managers, and supply chain managers.

SMEs were randomly selected from important industrial cities, including Delhi, Mumbai, Bangalore, Chennai, Kolkata, Chandigarh, and Ahmadabad, using the IndiaMart business directory, the most comprehensive business directory of firms in India. A professional market research firm was hired to conduct the data collection. The firm contacted the target SMEs by telephone to identify and verify the informant who could answer the survey questions and to solicit his/her participation in the survey, resulting in a sample of 550 participants. The firm collected questionnaires from 112 SMEs through face-to-face interviews with the appropriate respondents. One month later, a further 38 questionnaires were collected, leading to a total of 150 questionnaires, giving a response rate of $27.3 \%$ (150/550). Early and late responses on demographic characteristics, including industry, R\&D investment, training budget, and annual 
sales were compared with the t-statistics showing no significant differences, indicating that non-response bias does not appear to be a major concern in this study (Fawcett et al. 2014). The demographic profile of the SMEs is shown in Table 1.

\section{Insert Table 1 here}

This study relied on a single respondent to provide responses for both dependent and independent variables which creates concerns for common method bias (Fawcett et al. 2014; Guide and Ketokivi 2015). Three techniques were applied to evaluate the common method bias (Podsakoff et al. 2003). First, Harman's single factor test was applied by including all items from the constructs in the study into a confirmatory factor analysis (CFA). The fit indices were $\chi^{2}(560)=3027.159$, Comparative Fit Index $(\mathrm{CFI})=0.368$, Tucker-Lewis Index $(\mathrm{TLI})=0.328$, and Root Mean Square Error of Approximation $($ RMSEA) $=0.172$. These results were below the acceptable values suggested by $\mathrm{Hu}$ and Bentler (1999), suggesting that a single factor cannot account for all the variance in the data. Second, the technique of controlling for the effects of an unmeasured latent methods factor was used. A CFA model (model A) including only traits and one (model B) including both traits and a common method factor were tested. The model fit indices of model B were marginally improved compared to model A (e.g. $\chi^{2} / \mathrm{df}$ changed from 1.709 (model A) to 1.687 (model B)). The loadings of the trait factors were significant in both models and the variance explained by the common method factor was $7.6 \%$. These suggest that the factor loadings are robust, although a common method factor was included (Podsakoff et al. 2003). Third, we applied the correlation marker technique by introducing a marker variable (MV) that was unrelated to the variables to represent and gauge the potential common method variance (Lindell and Whitney 2001). The MV used was competition intensity. The lowest positive correlation between competition intensity and other variables ( $\mathrm{r}=0.07$, insignificant) was used to adjust the construct correlations and statistical significance using the method suggested by Lindell and Whitney (2001). The results showed that none of the significant correlations turned insignificant after the adjustment. Therefore, we drew the conclusion that common method bias is not a serious problem in this study.

\subsection{Reliability and validity}

Reliability was assessed in terms of composite reliability and Cronbach's alpha. The composite reliabilities ranged from 0.828 to 0.961 and the Cronbach's alpha values ranged from 0.733 to 0.953 (Appendix), which are all above the recommended threshold value of 0.70 , suggesting adequate reliability. 
We used average variance extracted (AVE) and CFA to assess the convergent and discriminant validity. The AVE values range from 0.524 to 0.823 (Appendix), which are above the recommended threshold value of 0.50 , thereby demonstrating adequate convergent validity (Fornell and Larcker 1981). In addition, we built a CFA model in which each item was linked to its corresponding construct and the covariance among the constructs was freely estimated. The model fit indices were $\chi^{2}(545)=931.62$, CFI $=0.92$, TLI $=0.91$, and RMSEA $=$ 0.069, which were better than the threshold values recommended by $\mathrm{Hu}$ and Bentler (1999). The factor loadings ranged from 0.673 to 0.933 (Appendix) and the smallest t-statistic of the loadings was 5.846 which is significant at the $\mathrm{p}<0.01$ level, also suggesting adequate convergent validity.

Discriminant validity was assessed by comparing the square root of the AVE of each construct with the correlations between the focal construct and every other construct, with a square root higher than the correlation with other constructs suggesting discriminant validity. A comparison of all the correlations and square roots of the AVE values indicated adequate discriminant validity for all constructs (Table 2). We also assessed discriminant validity by building a constrained CFA model for every possible pair of constructs, in which the correlations between the paired constructs were fixed at 1.0. This was compared with the original unconstrained model, in which the correlations between constructs were freely estimated. A significant difference in the chi-square statistics between the constrained and unconstrained models indicates discriminant validity (Fornell and Larcker 1981). The results showed that the smallest chi-square difference was 22.21 which is significant at the $p<0.01$ level, indicating that discriminant validity is ensured.

Insert Table 2 here

Covariance-based structural equation modelling (CBSEM) was used to assess the measurement model. The technique has several assumptions (Kaplan 2009; Kline 2012). CFA analysis assumes reflective measurement (Kline 2012). The measurement was developed based on existing literature and hence the directionality assumption is valid. Factors and measurement errors are assumed to be uncorrelated and the omitted causes of different indicators are assumed to be all pairwise uncorrelated (Kline 2012). We checked the modification indices of the CFA model and found that the correlations between the factors and measurement errors and those between the measurement errors do not significantly change the model. Factors are also assumed to be continuous variables that represent a single domain (Kline 2012). We used a 7- 
point Likert-type scale and hence the factors can be viewed as continuous variables. We also conducted an exploratory factor analysis and the result shows that all of the indicators can be loaded onto the specific factor that they are intended to measure and that all of the factor loadings are larger than 0.40 . Therefore, the factors are unidimensional. Indicators of a measurement model are assumed to be internal consistent (Kline 2012). The reliability analysis indicates that the assumption is also valid. In addition, the joint distribution of the endogenous variables is assumed to be multivariate normal (Kline 2012). The largest absolute skewness and kurtosis values of all factors are 0.993 and 1.438 respectively, and hence all univariate distributions are normal. We checked all bivariate scatterplots and they are all linear. We also plotted the residuals of the regression analyses and the results show that the distributions of the residuals are homoscedastic. Moreover, CBSEM assumes that each unit of analysis has complete data (Kaplan 2009). We checked the data to ensure that there are no missing vales and the variables are unstandardized in the CFA analysis (Kline 2012). We randomly selected the sample and hence the observations are independent (Kline 2012). CBSEM also assumes no specification error (Kaplan 2009). The research model was developed based on the KBV and contingency theory and the CFA analysis included all factors of the model.

\section{Analysis and results}

We conduct Durbin-Wu-Hausman endogeneity test before testing the hypotheses (Antonakis et al. 2010). Following Ketokivi and McIntosh (2017)'s suggestion, we estimate and compare two structural models which include paths from intellectual capital and university knowledge to indigenous innovation and from indigenous innovation to business performance. The difference between the two models is that one allows a correlation between the disturbance terms of indigenous innovation and business performance and the other not. The result of the chi-square difference test between the two models $\left(\chi^{2}(1)=2.838\right)$ indicates that they are not significantly different at the $\mathrm{p}<0.05$ level.

Moderated regression analysis is used to test the hypotheses. The results are presented in Table 3 and 4. To mitigate the potential threat of multicollinearity, the independent and moderating variables are mean-centred prior to the formation of interaction terms, as recommended by Aiken and West (1991). Furthermore, we calculate variance inflation factors (VIFs) to assess multicollinearity. The largest VIF value is 2.04 , well below the benchmark of 10 (Aiken and West 1991).

In Table 3, Model 1 reveals that both intellectual capital $(b=0.412, \mathrm{p}<0.01)$ and university knowledge $(b=0.220, \mathrm{p}<0.01)$ are positively associated with indigenous innovation. Therefore, 
$\mathrm{H} 1$ and $\mathrm{H} 2$ are supported. We also find that $\mathrm{R} \& \mathrm{D}$ investment $(b=0.202, \mathrm{p}<0.05)$ is positively associated with indigenous innovation. However, the impact of training budget on indigenous innovation is not significant. Then, the interaction between intellectual capital and university knowledge is added in Model 2. The result indicates that it significantly improves indigenous innovation $(b=0.476, \mathrm{p}<0.01)$. Hence, H3 is supported. In Table 4, Model 1 shows that indigenous innovation significantly improves business performance $(b=0.332, \mathrm{p}<0.01)$, supporting $\mathrm{H} 4$.

Insert Table 3 and 4 here

Next, interaction terms are created to test the moderating effects of dysfunctional competition and environmental uncertainty on the impacts of intellectual capital and university knowledge on indigenous innovation (Table 3) and the impact of indigenous innovation on business performance (Table 4). The interactions between dysfunctional competition and intellectual capital and between dysfunctional competition and university knowledge are added in Model 3 (Table 3). The results show that dysfunctional competition significantly enhances the impact of intellectual capital on indigenous innovation $(b=0.259, \mathrm{p}<0.01)$, but it does not moderate the impact of university knowledge on indigenous innovation. The interaction between dysfunctional competition and indigenous innovation is added in Model 2 (Table 4). The result shows that dysfunctional competition positively moderates the impact of indigenous innovation on business performance $(b=0.370, \mathrm{p}<0.01)$. Hence, H5a and H5c are supported, but $\mathrm{H} 5 \mathrm{~b}$ is not. The findings reveal that the effect of intellectual capital on indigenous innovation and that of indigenous innovation on business performance are stronger when the level of dysfunctional competition is higher. The significant moderating effects suggest that the positive impact of intellectual capital on indigenous innovation and that of indigenous innovation on business performance are strengthened by dysfunctional competition. The nonsignificant moderating effect indicates that the positive impact of university knowledge on indigenous innovation is not influenced by dysfunctional competition. University knowledge thus has a similar effect on indigenous innovation no matter what the level of dysfunctional competition is. Similarly, the interactions between environmental uncertainty and intellectual capital and between environmental uncertainty and university knowledge are added in Model 4 (Table 3). The results show that environmental uncertainty significantly reduces the impact of university knowledge on indigenous innovation $(b=-0.163, \mathrm{p}<0.05)$, but it does not moderate the impact of intellectual capital on indigenous innovation. The interaction between environmental uncertainty and indigenous innovation is added in Model 3 (Table 4). The result 
shows that environmental uncertainty negatively moderates the impact of indigenous innovation on business performance $(b=-0.203, \mathrm{p}<0.01)$. Hence, H6c is supported, but H6a and $\mathrm{H} 6 \mathrm{~b}$ are not. The findings reveal that the effect of university knowledge on indigenous innovation and that of indigenous innovation on business performance are weaker when the level of environmental uncertainty is higher. The significant moderating effects suggest that the positive impact of intellectual capital on indigenous innovation and that of indigenous innovation on business performance are attenuated by environmental uncertainty. The nonsignificant moderating effect indicates that the positive impact of intellectual capital on indigenous innovation is not influenced by environmental uncertainty. Intellectual capital thus has a similar effect on indigenous innovation no matter what the level of environmental uncertainty is.

We test the indirect effects of intellectual capital and university knowledge on business performance through indigenous innovation using the bias-corrected bootstrapping method with a 95\% confidence level and 5000 samples (Preacher, Rucker, and Hayes 2007). The results show that the bias-corrected $95 \%$ confidence interval for the indirect effect of intellectual capital on business performance through indigenous innovation is $(-0.011,0.150)$ and that the bias-corrected $95 \%$ confidence interval for the indirect effect of university knowledge on business performance through indigenous innovation is $(-0.004,0.164)$. Therefore, neither intellectual capital nor university knowledge affects business performance indirectly through indigenous innovation (Preacher, Rucker, and Hayes 2007).

\section{Discussion and conclusions}

\subsection{The relationships among intellectual capital, university knowledge, indigenous innovation, and business performance}

The findings that intellectual capital and university knowledge increase indigenous innovation are consistent with existing empirical results on the performance outcomes of intellectual capital (Subramaniam and Youndt 2005; Hsu and Sabherwal 2012) and universityindustry collaboration (Sherwood and Covin 2008; Un, Cuervo-Cazurra, and Asakawa 2010; Un and Asakawa 2015). In the Global Innovation Index, India was ranked at the 28th and 48th positions in terms of the QS university ranking and university-industry collaboration in $R \& D$, respectively (Dutta, Lanvin, and Wunsch-Vincent 2015). Hence universities have established a solid foundation for the development of innovation capabilities and university knowledge plays a significant role in promoting industrial innovation in India (Parayil and D'Costa 2009). The Indian SMEs achieved a growth rate of $18.74 \%$ in 2015 and accounted for around $40 \%$ in 
total manufacturing output (Ministry of Micro Small and Medium Enterprises 2016). The economic development in the last decades allows Indian SMEs to accumulate intellectual capital which can be applied to develop new products and processes (Small and Medium Business Development Chamber of India 2016). In addition, we find that intellectual capital and university knowledge are complementary in improving indigenous innovation, which is consistent with the argument that new knowledge is created through the interactions between internal and external knowledge (Zahra and George 2002; Zhang et al. 2015). Universities are at the upstream of knowledge chains and usually provide a firm knowledge with wide breadth and large contextual distance (Un and Asakawa 2015; Un, Cuervo-Cazurra, and Asakawa 2010). Hence university knowledge must be absorbed and processed which relies on a SME's existing knowledge base (Kotha, George, and Srikanth 2013; Zhang et al. 2015). Therefore, the interaction between intellectual capital and university knowledge enables SMEs to create new knowledge which leads to indigenous innovation ( $\mathrm{Li}$ et al. 2010). Moreover, resources invested in R\&D enable a SME to develop capabilities and explore new knowledge domains, enhancing indigenous innovation. Although investments in training can improve employees' skills, they usually focus on distributing existing knowledge and best practices among employees (Youndt, Subramaniam, and Snell 2004). Therefore, the impact of training budget on indigenous innovation is not significant.

We find that indigenous innovation is positively associated with business performance, which is consistent with existing empirical results in other emerging markets ( $\mathrm{Li}$ and AtuaheneGima 2001; McMahon and Thorsteinsdóttir 2013). As SMEs typically lack resources to gain competitive advantages through economies of scale and scope, indigenous innovations play critical roles for SMEs to improve productivity and differentiate themselves with competitors, increasing business performance (Mathur, Mittal, and Dangayach 2012; Thakkar, Kanda, and Deshmukh 2013; Waehrens, Slepniov, and Johansen 2015).

\subsection{The moderating effects of dysfunctional competition and environmental uncertainty}

In India, civil servants are known to accept bribes and engage in other corrupt behavior (Miller and Kim 2016). In the absence of a well-functioning legal and regulatory framework (Dutta, Lanvin, and Wunsch-Vincent 2015), Indian SMEs face dysfunctional competition (Li and Atuahene-Gima 2001). It is costly for them to enforce contracts and protect business interests through legal means if partners behave opportunistically. This problem is especially severe for $R \& D$ collaboration because of the risks, uncertainties, and the intensity of knowledge sharing associated with collaborative innovation (Wang, Yeung, and Zhang 2011). Relying on intellectual capital for innovation ensures that new ideas and knowledge will not 
be leaked to outsiders. Therefore, when dysfunctional competition is intense, intellectual capital plays a more important role in developing indigenous innovation. University scholars focus on research and teaching and they usually do not have the intention and capabilities to imitate a SME's new products (Kotha, George, and Srikanth 2013). Researchers also think highly of their reputation. Leaking a SME's knowledge to markets thus is not in researchers' interests and they will honor contracts and agreements even if opportunistic behavior will not be severely punished (Un and Asakawa 2015). Therefore, dysfunctional competition does not influence the impact of university knowledge on indigenous innovation. Indigenous innovations are based on a SME's internal capabilities and patents and usually in preparadigmatic design stage (Teece 1986; Li et al. 2011). As a result, SMEs can enjoy the exclusive rights brought by indigenous innovations even when dysfunctional competition is intense because the nature of the technologies embedded in the innovations makes them difficult for competitors to copy (Teece 1986; Li and Atuahene-Gima 2001; Sheng, Zhou, and Lessassy 2013). Therefore, dysfunctional competition enhances the impact of indigenous innovation on business performance.

Customers' preferences and technologies change quickly in India because of the high speed economic growth and globalisation (World Bank 2015). We find that environmental uncertainty does not influence the impact of intellectual capital on indigenous innovation. The reason might be that environmental uncertainty has mixed influences on the impacts of the components of intellectual capital on indigenous innovation, leading to an insignificant moderating effect. Structural capital reflects the knowledge residing within a SME's processes and systems, which is based on the SME's past experiences and best practices (Hsu and Wang 2012). When environmental uncertainty is high, structural capital may become outdated and hence environmental uncertainty reduces the effect of structural capital on indigenous innovation. Human and social capital reflect employees' knowledge and expertise and the knowledge embedded in personal relationships (Lee, Swink, and Pandejpong 2011). Although environmental uncertainty makes employees' current knowledge and skills obsolete, employees with high capabilities and have cooperative relationships among themselves are more likely to create new knowledge to keep up with changing environments. Hence environmental uncertainty amplifies the impacts of human and social capital on indigenous innovation. Although universities possess broad knowledge domains that can extend SMEs' knowledge boundaries to respond to new customer requirements and technology development (Un, Cuervo-Cazurra, and Asakawa 2010), they are at the upstream of knowledge chains and have large contextual knowledge distance (Un and Asakawa 2015; Alexander and Childe 2013). 
Hence university knowledge needs to be assimilated and transformed before it can be applied in innovation (Zahra and George 2002; Zhang et al. 2015). It may take a long time for a SME to transfer new market requirements to universities and absorb university knowledge because it typically lacks resources and capabilities (Thakkar, Kanda, and Deshmukh 2013). In an uncertain environment, long lead-times can make university knowledge out of date for innovation. Therefore, environmental uncertainty reduces the value of university knowledge on indigenous innovation. When environmental uncertainty is high, products become obsolete quickly and SMEs are unable to gain super profits from indigenous innovations for a long period. Therefore, environmental uncertainty negatively moderates the impact of indigenous innovation on business performance.

\subsection{Theoretical contributions}

This study contributes to literature in three ways. First, this study provides empirical evidence that university knowledge improves SMEs' indigenous innovation, which sheds light on how universities contribute to SMEs' operations (Ahrweiler, Pyka, and Gilbert 2011; Mathur, Mittal, and Dangayach 2012; Sherwood and Covin 2008). The findings also show that the effect of university knowledge on indigenous innovation is enhanced by intellectual capital but reduced by environmental uncertainty. These increase current understandings on the factors affecting the effectiveness of university-industry collaboration and the commercialisation of university knowledge in SMEs (Bruneel, D'Este, and Salter 2010; Maietta 2015). This study thus suggests that researchers should consider environmental uncertainty and a SME's intellectual capital when investigating the effects of university-industry collaboration.

Second, this study reveals that the effect of intellectual capital on indigenous innovation is amplified by dysfunctional competition. The majority of empirical studies focus on intellectual capital's direct effects on innovation (Subramaniam and Youndt 2005; Hsu and Wang 2012; Hsu and Sabherwal 2012). This study discovers that the impacts of intellectual capital can be affected by institutional environments, enhancing current understandings on when intellectual capital is more important for SMEs' operations (Youndt, Subramaniam, and Snell 2004). In addition, the findings show that intellectual capital contributes to indigenous innovation not only directly but also by enhancing the impact of university knowledge, providing insights into how knowledge management practices jointly improve the effectiveness of SMEs' operations (Liu et al. 2014; Aboelmaged 2014). Hence, researchers should take the interactions between intellectual capital and university knowledge into consideration when investigating the performance outcomes of intellectual capital. We also suggest that a contingency perspective 
should be adopted when exploring the effectiveness of SMEs' knowledge management practices (Li and Atuahene-Gima 2001; Sheng, Zhou, and Lessassy 2013).

Third, this study provides empirical evidence on the antecedents and consequences of indigenous innovation ( $\mathrm{Li}$ et al. 2010; $\mathrm{Li}$ et al. 2011). The results show that indigenous innovation improves SMEs' business performance, enhancing extant knowledge on the roles played by indigenous innovation in SMEs' operations (Mathur, Mittal, and Dangayach 2012; Waehrens, Slepniov, and Johansen 2015). In addition, we find that the impact of indigenous innovation on business performance is enhanced by dysfunctional competition but reduced by environmental uncertainty. By linking indigenous innovation with a country's institutional and business environments, this study provides insights into when SMEs can profit from indigenous innovation (Teece 1986).

\subsection{Practical implications}

This study can provide guidelines for SMEs to improve the effectiveness of their operations through knowledge management. First, we suggest SMEs establish and maintain collaborative relationships with universities and develop intellectual capital for improving innovation. Processes should be developed to obtain various kinds of knowledge from universities, including methods for implementing technologies and troubleshooting, ways for getting around limitations of technologies, rules for utilising technologies in the most efficient manner, details regarding the components of technologies, and documentation regarding technology quality control. In addition, procedures and communication channels should be developed for employees in different functional departments to interact with each other when the need arises. Formal and informal social events such as workshops, seminars, and conferences should be organised to help employees to build and maintain relationships and to enable them to discuss problems openly. Standard operating procedures, systems, databases, and manuals should be created to keep a SME's past experiences and best practices on university-industry collaboration and innovation. A SME should hire employees with high levels of skills and useful experiences in their respective jobs. Training programs should also be devised to update employees' skills and knowledge. Second, we suggest SMEs invest in intellectual capital and collaboration with university at the same time to capture their complementary effects. Managers should update existing systems, processes, and manuals using the knowledge acquired from universities frequently. Managers should also evaluate and absorb university knowledge using prior related knowledge. Third, we suggest SMEs take a contingency view and managers should be aware that the effects of knowledge management and innovation are moderated by institutional and business environments. If there are increased unfair or unlawful 
competitive practices in markets and the competition laws are ineffective, SMEs should rely more on intellectual capital for indigenous innovation. If it is difficult to predict changes in markets and technology development, a SME should rely less on collaboration with universities for indigenous innovation. Moreover, managers should understand that the positive impact of indigenous innovation on business performance is reduced by environmental uncertainty but increased by dysfunctional competition. Therefore, SMEs should rely more on their own resources and capabilities for new product development when the level of dysfunctional competition is high. Managers should be warned that they may profit less from indigenous innovation in an uncertain environment.

This study can also provide suggestions for government officials on how to help SMEs. First, we suggest that more resources should be invested in improving the quality of universities and research institutes. Government support should be designed to promote university-industry collaboration. For example, public platforms should be built and social events should be organised for university researchers and SMEs to know each other and establish relationships. Financial and legal support such as tax holidays, grants supporting commercialisation of research outputs, and contracting and IP filing support should be provided to facilitate university-industry collaboration. Second, government officials should evaluate and accredit SMEs based on their intellectual capital. Special agents, such as technology transfer offices, should be established to bridge the knowledge gaps between universities and SMEs and help them to find partners. Third, programs and policies should be devised to improve institutional and business environments to support R\&D collaboration and innovation. For example, officials should frequently survey markets and publish reports on market development trends, and organise forums or conferences to provide information on newly developed technologies. Financial and technical support should also be provided to help SMEs to adopt advanced technologies. Moreover, special bureaus and multi-agency task forces should be established to fight corruption and strengthen law enforcement. New competition laws should be passed to provide better protection for IP rights.

\subsection{Limitations and future research directions}

This study has limitations that open avenues for future research. First, this study is conducted in one country and hence the lack of generalisability is a limitation. Future studies could replicate this study in other countries to validate and generalise the findings. Second, this study focuses on university knowledge. Researchers argue that a firm can also obtain knowledge from other partners including suppliers, customers, and competitors (Zhang et al. 2015; Un and Asakawa 2015). Future studies could explore the impacts of R\&D collaboration 
with different partners on SMEs' operations. Third, this study focuses on the effects of the overall dysfunctional competition and environmental uncertainty managers perceived. A firm faces different types of dysfunctional competition and environmental uncertainty which may influence the impacts of knowledge management practices and innovation in different ways. Exploring the distinctive effects of different types of dysfunctional competition and environmental uncertainty on SMEs' operations could be an interesting research topic. Fourth, we perform the statistical analysis using a relatively small sample, which is a limitation. Fifth, this study uses one informant per observational unit and hence common method bias cannot be eliminated (Ketokivi and Schroeder 2004). Therefore, data collection is a major limitation of this study. Future studies could collect data from multiple informants or use hard data from financial reports to mitigate the common method bias (Fawcett et al. 2014). Sixth, this study tests the research model using cross-sectional survey data and hence we cannot establish causal relationships (Guide and Ketokivi 2015). Future studies could adopt longitudinal or experimental designs to address the problem of endogeneity.

\section{References}

Aboelmaged, M.G. 2014. "Linking operations performance to knowledge management capability: The mediating role of innovation performance." Production Planning \& Control 25 (1):44-58.

Ahrweiler, P., A. Pyka, and N. Gilbert. 2011. "A new model for university-industry links in knowledge-based economies." Journal of Product Innovation Management 28 (2):218235.

Aiken, L.S., and S.G. West. 1991. Multiple regression: Testing and interpreting interactions, Thousand Oaks: Sage Publishing.

Al-Ashaab, A., M. Flores, A. Doultsinou, and A. Magyar. 2011. "A balanced scorecard for measuring the impact of industry-university collaboration." Production Planning \& Control 22(5/6):554-570.

Alexander, A.T., and S.J. Childe. 2013. "Innovation: A knowledge transfer perspective." Production Planning \& Control 24 (2/3):208-225.

Antonakis, J., S. Bendahan, P. Jacquart, and R. Lalive. 2010. "On making causal claims: A review and recommendations." The Leadership Quarterly 21:1086-1120.

Bruneel, J., P. D'Este, and A. Salter. 2010. "Investigating the factors that diminish the barriers to university-industry collaboration." Research Policy 39:858-868. 
Chen, I. J., and A. Paulraj. 2004. "Towards a theory of supply chain management: The constructs and measurements." Journal of Operations Management 22 (2):119-150.

Desai, D.A. 2008. "Cost of quality in small- and medium-sized enterprises: Case of an Indian engineering company." Production Planning and Control 19(1):25-34.

Dutta, S., B. Lanvin, and S. Wunsch-Vincent. 2015. "The Global Innovation Index 2015: Effective innovation policies for development." Cornell University, INSEAD, and the World Intellectual Property Organization https://www.globalinnovationindex.org/userfiles/file/reportpdf/GII-2015-v5.pdf. Accessed 29/09/2016.

Fawcett, S.E., M.A. Waller, J.W. Miller, M.A. Schwieterman, B.T. Hazen, and R.E. Overstreet. 2014. "A trail guide to publishing success: Tips on writing influential conceputal, qualitative, and survey research." Journal of Business Logistics 35(1):1-16.

Forbes, N. 2014. "Higher education in India: Growth with challenges." In The Global Innovation Index 2014: The human factor in innovation, edited by S. Dutta, B. Lanvin and S. Wunsch-Vincent, 85-91. https://www.globalinnovationindex.org/userfiles/file/reportpdf/gii-2014-v5.pdf. Accessed 29/09/2016.

Fornell, C., and D.F. Larcker. 1981. "Evaluating structural equation models with unobservable variables and measurement error." Journal of Marketing Research 18 (1):29-50.

Garengo, P. and M.M. Sharma. 2014. "Performance measurement system contingency factors: A case analysis of Italian and Indian SMEs". Production Planning \& Control 25(3):220-240.

Grant, R.M. 1996. "Toward a knowledge-based theory of the firm". Strategic Management Journal 17:109-122.

Guide, V. D. R., and M. Ketokivi. 2015. "Notes from the editors: Redefining some methodological criteria for the journal". Journal of Operations Management (37):v-viii.

Hu, L., and P.M. Bentler. 1999. "Cutoff criteria for fit indices in covariance structure analysis: Conventional criteria versus new alternatives". Structural Equation Modeling 6(1):155.

Hsu, I., and R. Sabherwal. 2012. "Relationship between intellectual captial and knowledge management: An emprical investigation." Decision Sciences 43 (3):489-524.

Hsu, L., and C. Wang. 2012. "Clarifying the effect of intellectual capital on performance: The mediating role of dynamic capability." British Journal of Management 23 (2):179-205. 
Kaplan, D. 2009. Structional equation modeling: Foundations and extensions. Thousand Oaks: SAGE Publications, Inc.

Kaste, F.E. and J.E. Rosenzweig. 1985. Organization and management: A systems and contingency approach. New York:McGraw-Hill, Inc.

Ketokivi, M.A. and R.G. Schroeder. 2004. "Perceptual measures of performance: Fact or fiction?" Journal of Operations Management 22:247-264.

Ketokivi, M. and C.N. McIntosh. 2017. "Addressing the endogeneity dilemma in operations management: Theoretical, empirical, and pragmatic considerations." Journal of Operations Management 52:1-14.

Kline, R. B. 2012. Assumptions of structural equation modeling. In Hoyle R. (Ed.), Handbook of structural equation modeling. New York: Guilford Press.

Kotha, R., G. George, and K. Srikanth. 2013. "Bridging the mutual knowledge gap: Coordination and the commercialization of university science." Academy of Management Journal 56 (2):498-524.

Kozhikode, R.K., and J. Li. 2012. "Political pluralism, public policies, and organizational choices: Banking branch expansion in India, 1948-2003." Academy of Management Journal 55 (2):339-359.

Kumar, M., J. Antony, R.K. Singh, M.K. Tiwari, and D. Perry. 2006."Implementing the Lean Sigma framework in an Indian SME: A case study". Production Planning \& Control 17(4):407-423.

Lawrence P.R. and J.W. Lorsch. 1986. Organization and environment: Managing organization differentiation and integration. Boston: Harvard University Press.

Li, H., and K. Atuahene-Gima. 2001. "Production innovation strategy and the performance of new technology ventures in China " Academy of Management Journal 44 (6):11231134.

Li, Y., X. Li, Y. Liu, and R. Barnes. 2011. "Knowledge communication, exploitation and endogenous innovation: The moderating effects of internal controls in SMEs." $R \& D$ Management 41 (2):156-172.

Li, Y., C. Zhang, Y. Liu, and M. Li. 2010. "Organizational learning, internal control mechanisms, and indigenous innovation: The evidence from China." IEEE Transactions on Engieering Management 57 (1):63-77.

Lindell, M.K., and D.J. Whitney. 2001. "Accounting for common method variance in crosssectional research designs". Journal of Applied Psychology 86(1):114-121. 
Liu, S., J. Moizer, D. Kasturiratune, and U. Jayawickrama. 2014. "A knowledge chain management framework to support integrated decisions in global supply chains." Production Planning \& Control 25 (8):639-649.

Lee, J.Y., M. Swink, and T. Pandejpong. 2011. "The roles of worker expertise, information sharing quality, and psychological safety in manaufacturing process innovation: An intellecutal captial perspective". Production and Operations Management 20(4):556570.

Maietta, O.W. 2015. "Determinants of university-firm R\&D collaboration and its impact on innovation: A perspective from a low-tech industry." Research Policy 44 (7):1341-1159.

Mathur, A., M.L. Mittal, and G.S. Dangayach. 2012. "Improving productivity in Indian SMEs." Production Planning \& Control 23 (10-11):754-768.

McMahon, D., and H. Thorsteinsdóttir. 2013. "Pursuing endogenous high-tech innovation in developing countries: A look at regenerative medicine innovation in Brazil, China and India." Research Policy 42:965-974.

Miller, T., and A.B. Kim. 2016. "2016 Index of Economic Freedom." The Heritage Foundation. http://www.heritage.org/index/. Accessed 29/09/2016.

Ministry of Micro Small and Medium Enterprises. 2016. "Annual report 2015-16." http://msme.gov.in/WriteReadData/DocumentFile/MEME\%20ANNUAL\%20REPOR T\%202015-16\%20ENG.pdf. Accessed 29/09/2016.

Nahapiet, J., and S. Ghoshal. 1998. "Social capital, intellectual capital, and the organizational advantage." Academy of Management Review 23 (2):242-266.

Nonaka, I. 1994. "A dynamic theory of organisational knoweldge creation". Organization Science 5(1):14-37.

Parayil, G., and A.P. D'Costa. 2009. "The new Asian innovation dyamics: China and India in perspective." Technology, globalisation and development England: Palarave Macmillan.

Podsakoff, P.M., S.B. MacKenzie, J.Y. Lee, and N.P. Podsakoff. 2003. "Common method biases in behavioral research: A critical review of the literature and recommended remedies." Journal of Applied Psychology 88 (5):879-903.

Prahalad, C.K., and R.A. Mashelkar. 2010. "Innovation’s holy grail." Harvard Business Review 88 (7/8):132-141.

Preacher, K., D. D. Rucker, and A.F. Hayes. 2007. "Addressing moderated mediation hypotheses: Theory, methods, and prescriptions". Multivariate Behavioural Research 42 (1):185-227. 
Sheng, S., K. Zhou, and L. Lessassy. 2013. "NPD speed vs. Innovativeness: The contingent impact of institutional and market environments." Journal of Business Research 66 (11):2355-2362.

Sherwood, A.L., and J.G. Covin. 2008. "Knowledge acquisition in university-industry alliances: An empirical investigation from a learning theory perspective." Journal of Product Innovation Management 25 (2):162-179.

Small and Medium Business Development Chamber of India. "About MSMEs in India." http://www.smechamberofindia.com/About_MSMEs.aspx. Accessed 29/09/2016.

Subramaniam, M., and M.A. Youndt. 2005. "The influence of intellectual capital on the types of innovative capabilties." Academy of Management Journal 48 (3):450-463.

Teece, D.J. 1986. "Profiting from technological innovation: Implications for integration, collaboration, licensing and public policy." Research Policy 15 (6):285-305.

Thakkar, J., A. Kanda, and S.G. Deshmukh. 2013. "Supply chain issues in SMEs: Select insights from cases of Indian origin." Production Planning \& Control 24 (1):47-71.

Un, C.A., and K. Asakawa. 2015. "Types of R\&D collaborations and process innovation: The benefit of collaborating upstream in the knowledge chain." Journal of Product Innovation Management 32 (1):138-153.

Un, C.A., A. Cuervo-Cazurra, and K. Asakawa. 2010. "R\&D collaborations and product innovation." Journal of Product Innovation Management 27 (5):673-689.

Vickery, S.K., J. Jayaram, C. Droge, and R. Calantone. 2003. "The effects of an integrative supply chain strategy on customer service and financial performance: An analysis of direct versus indirect relationships." Journal of Operations Management 21 (5):525539.

Waehrens, B.V., D. Slepniov, and J. Johansen. 2015. "Offshoring practices of Danish and Swedish SMEs: Effects on operations configuration." Production Planning \& Control 26 (9):693-705.

Wamba, S.F., A. Gunasekaran, M. Bhattacharya, and R. Dubey. 2016. "Determinants of RFID adoption intention by SMEs: An empirical investigation." Production Planning \& Control 27 (12):979-990.

Wang, L., J.H.Y. Yeung, and M. Zhang. 2011. "The impact of trust and contract on innovation performance: The moderating role of environmental uncertainty." International Journal of Production Economics 134 (1):114-122. 
World Bank. 2014. "Doing business 2015: Going beyond efficiency." The World Bank Group. http://www.doingbusiness.org/reports/global-reports/doing-business-2015.Accessed 29/09/2016.

World Bank. 2015. "The world bank data indicator." The World Bank Group. http://data.worldbank.org/. Accessed 29/09/2016.

Youndt, M.A., M. Subramaniam, and S.A. Snell. 2004. "Intellectual capital profiles: An examination of investments and returns." Journal of Management Studies 41 (2):335361.

Zahra, S.A., and G. George. 2002. "Absorptive capacity: A review, reconceptualization, and extension." Academy of Management Review 27 (2):185-203.

Zhang, M., X. Zhao, M. Lyles, and H. Guo. 2015. "Absorptive capacity and mass customization capability." International Journal of Operations \& Production Management 35 (9):1275-1294

Zhang, S., Z. Wang, X. Zhao, and M. Zhang. 2017. "Effects of institutional support on innovation and performance: Roles of dysfunctional competition". Industrial Management \& Data Systems 117(1):50-67.

Appendix Measurement items

\begin{tabular}{|l|l|}
\hline \multicolumn{1}{|c|}{ AVE=0.524; C.R.=0.919; Alpha=0.903 } & Loading \\
\hline Intellectual capital $\quad$ AValling each other & .727 \\
\hline $\begin{array}{l}\text { Employees from different departments feel comfortable cale } \\
\text { when the need arises. }\end{array}$ & .734 \\
\hline People are quite accessible to each other in the company. & .729 \\
\hline We are able to discuss problems and tough issues openly in the company. & .673 \\
\hline Standard operating procedures are in place. & .719 \\
\hline $\begin{array}{l}\text { Much of this company's knowledge is contained in manuals, archives, or } \\
\text { databases. }\end{array}$ & .717 \\
\hline $\begin{array}{l}\text { Our company embeds much of its knowledge and information in structures, } \\
\text { systems, and processes. }\end{array}$ & .758 \\
\hline Employees in the company are highly skilled in their respective jobs. & .709 \\
\hline $\begin{array}{l}\text { Employees in the company are considered among the best people in our } \\
\text { industry. }\end{array}$ & .720 \\
\hline Every employee in the company has useful experience. & .750 \\
\hline Our employees always develop new ideas and knowledge. & .893 \\
\hline University knowledge AVE=0.712; C.R.=0.960; Alpha=0.953 & .796 \\
\hline Unstated methods for implementing the technology. & .906 \\
\hline Unwritten methods for troubleshooting. & .807 \\
\hline Ways for getting around obstacles or limitations of the technology. & .869 \\
\hline Unwritten rules for utilizing the technology in the most efficient manner. \\
\hline Written specifications related to the technology. & \\
\hline
\end{tabular}




\begin{tabular}{|c|c|}
\hline Written details regarding the components of the technology. & .852 \\
\hline Step-by-step procedures for troubleshooting the technology. & .819 \\
\hline Documentation regarding technology quality control. & .829 \\
\hline \multicolumn{2}{|l|}{ Indigenous innovation $\mathrm{AVE}=0.623 ; \mathrm{C} . \mathrm{R} .=0.853 ; \mathrm{Alpha}=0.778$} \\
\hline $\begin{array}{l}\text { High rate of new products are developed by using the company's own } \\
\text { resources and capabilities. }\end{array}$ & .707 \\
\hline The patents used in the products are exclusively owned by the company. & .800 \\
\hline High rate of new products are developed by using the company's own patents. & .926 \\
\hline High number of the patents designed by the company have been authorized. & .704 \\
\hline \multicolumn{2}{|l|}{ Business performance $\mathrm{AVE}=0.666 ; \mathrm{C} . \mathrm{R} .=0.931 ; \mathrm{Alpha}=0.908$} \\
\hline Profit & .832 \\
\hline Market share & .832 \\
\hline Sales growth & .723 \\
\hline Market share growth & .821 \\
\hline Return on investment & .864 \\
\hline \multicolumn{2}{|l|}{ Dysfunctional competition AVE $=0.823 ;$ C.R. $=0.961 ;$ Alpha $=0.953$} \\
\hline Unlawful competitive practices such as illegal copying of new products. & .933 \\
\hline $\begin{array}{l}\text { Counterfeiting of your company's own products and trademarks by other } \\
\text { companies. }\end{array}$ & .924 \\
\hline $\begin{array}{l}\text { Ineffective market competition laws to protect your company's intellectual } \\
\text { property. }\end{array}$ & .903 \\
\hline Increased unfair competitive practices by other companies in the industry. & .867 \\
\hline \multicolumn{2}{|l|}{ Environmental uncertainty AVE $=0.528 ;$ C.R. $=0.828 ;$ Alpha $=0.733$} \\
\hline It is difficult to predict changes of the market. & .745 \\
\hline The volume or composition of demand is difficult to predict. & .714 \\
\hline The technology in our industry is changing rapidly. & .676 \\
\hline $\begin{array}{l}\text { It is very difficult to forecast the technology development direction in our } \\
\text { industry. }\end{array}$ & .767 \\
\hline
\end{tabular}

Note: $C . R .=$ composite reliability; alpha $=$ Cronbach's alpha; $A V E=$ average variance extracted . 